\title{
The Mysterious, and Potentially Revolutionary, Immunological Properties of Transfer Factor: A Review
}

\author{
Robert Root-Bernstein, Ph. D. \\ Department of Physiology \\ 2174 Biomedical and Physical Sciences Building \\ Michigan State University \\ East Lansing, MI 48824 USA \\ rootbern@msu.edu
}

\begin{abstract}
Transfer factor is the name given to material derived from activated lymphocytes that is probably composed of a complex of a peptide and a short segment of RNA and which has the reported ability to transfer specific $\mathrm{T}$ cell immunity to uncommitted lymphocytes. Many independent groups around the world reported isolating transfer factors between 1955 and 1990 and demonstrating their ability to transfer passive immunity from one animal or individual to another, often within 24 hours of inoculation. Such activity is potentially revolutionary both in making $\mathrm{T}$ cell vaccines readily manufacturable and also because the existence of transfer factors would undermine the basic assumptions of the clonal selection theory, which currently dominates immunological theory. Unfortunately, lack of the microanalytical and synthetic techniques required to properly identify transfer factors, combined with safety factors associated with it derivation from blood sources susceptible to HIV and prion infections, put an end to transfer factor research after 1990. This paper reviews the evidence supporting transfer factor activity and suggests that this potentially revolutionary concept be resurrected and subjected to renewed scrutiny in light of CRISPR-Cas mechanisms and because of its potential to make possible $\mathrm{T}$ cell vaccination and provide a novel basis for understanding immunological function.
\end{abstract}

Key Words: CRISPR, clonal selection, totipotent, multipotent, T cell receptors, B cell receptors, precommitted, lymphocyte, $\mathrm{T}$ cell vaccine, $\mathrm{T}$ cell vaccination

\section{Introduction: The Controversial Nature of Transfer Factor}

Most immunologists have never heard of transfer factor (TF) despite the fact that it may be - emphasis on "may" — one of the most important discoveries ever made in immunology. Transfer factor (TF) was discovered in 1955 by Henry Sherwood Lawrence. Lawrence was able to transfer immunity to unexposed animals using small molecules derived from leukocytes derived from animals immunized against streptococcal antigens (Lawrence 1955; 1969; 1974). Subsequent research would show that $\mathrm{TF}$ is probably composed of a combination of peptide and RNA components that have the ability to initiate Th1 (cellular) immunity, suggesting its potential to serve as a form of T-cell vaccination (e.g., Arala et al., 1974; Fudenberg and Pizza, 1974; Kirkpatrick et al., 1985a; 1985b; Viza, et al., 1987). Since there are no general methods for producing $\mathrm{T}$ cell vaccines at present, TF would be revolutionary. Many investigators reported that TF even works in immunosuppressed individuals to stimulate immune responses against opportunistic infections that these individuals cannot mount themselves 
(e.g., Kirkpatrick and Smith, 1976; Viza, et al., 1987; Fernandez-Ortega, et al., 1996; Masi, et al., 1996). The isolation and identification of disease-specific TFs could therefore make it possible to treat diseases of impaired cellular immunity such as AIDS and for vaccinating against $\mathrm{T}$-cell mediated diseases such as malaria and tuberculosis.

During its heyday from the 1970s through 1990s, several hundred papers were published about TF touting various clinical possibilities, describing its specificity, and exploring its chemical nature. Today, the transfer factor field is moribund. There has been no active laboratory research conducted anywhere in the world except for China (e.g., $\mathrm{Xu}$, et al., 2006; Li, et al, 2010) on TF for the past decade, and only six groups outside of Asia have used TF clinically in recent years (e.g., Luna-Baca, et al., 2007; Fabre, et al. 2004 [tuberculosis treatment]; Pineda, et al., 2005 [glioma therapy]; Masi, et al, 1996 and Borysov, et al., 1998 [candidiasis]; Liubchenko, et al., 1997 [bacterial infections]) . (The previous statement ignores a number of U. S., E. U., and Chinese commercial companies selling products under the "transfer factor" name that appear to have no chemical relationship to the TF being discussed here, e.g., http://www.transferfactor.com/Home/Faq and http://www.4life.com/). The thesis of this review is that TF research was abandoned prematurely.

My belief is that TF was abandoned prematurely, largely because of four problems, two of which can now be solved, while the remaining two involve considerations that make TF all the more interesting. First, the analytical techniques required to characterize $\mathrm{TF}$ at a molecular level did not exist until the past decade, so that the molecular nature of TF has remained a mystery throughout the 1950s through 1990s (Rozzo and Kirkpatrick, 1992; Kirkpatrick, 2000). Second, the fact that TF was derived from blood created major hurdles to its safe development in the AIDS and prion era and would have made it very difficult to obtain FDA approval for clinical use. Thus, major pharmaceutical companies and government funding agencies refused to fund research in this area for fear of spreading viral or other infections (personal communications). Third, proponents of the dominant theory of immunology, the clonal selection theory (CST), explicitly stated that there was no place for TF. Indeed, proof of TF activity and characterization of its composition would have undermined the need for clonal selection. Fourth, TF researchers provided no mechanism by which TF could function, leaving its actions unexplained and, from a CST perspective, incomprehensible. The first two challenges can now be solved by microanalytical techniques and synthetic methods for producing pure peptides and RNA aptamers developed over the past two decades. TF, assuming it exists, can almost certainly be identified chemically and made artificially, thereby bypassing any infectious risks. The third challenge involving TF's threat to CST is one that deserves further examination. And I will provide a possible mechanism for TF function at the end of this paper.

Begin with the threat that TF posed (and continues to pose) to CST. Macfarlane Burnet, the Nobel Prize winner who invented clonal selection theory, addressed the challenge of TF to immunological theory in a 1974 article, noting that, "Widespread recent interest in the transfer factor of $\mathrm{H}$. S. Lawrence and its possible therapeutic applications has not yet led to an interpretation of the phenomenon that can bring it into a satisfactory relationship with standard immunological theory... To me, and I suspect to most immunologists, the major challenge of Lawrence's results is to find a place for them within the bounds of orthodox immunological theory." (Burnet, 1974, 1). David Talmage 
(1986) reiterated this problem a dozen years later and Dimitri Viza analyzed in great detail the challenges that TF posed to CST that still persisted after more than twenty years and the ire that TF therefore raised among conservative immunologists (Viza, 1996). Briefly stated, current dogma, based on Burnet's clonal selection theory, maintains that the immune system generates all possible $\mathrm{B}$ and $\mathrm{T}$ cell clones required to respond to any antigen during early organismal development. Each clone is therefore predetermined to produce a single, unique T cell receptor, B cell receptor or antibody sequence. Direct exposure of the antigen to a $\mathrm{T}$ or $\mathrm{B}$ cell clone bearing an appropriately complementary $\mathrm{T}$ or B cell receptor activates clonal amplification. Only those T or B cells activated by binding of the antigen to their receptor are so amplified. Burnet's theory (and its more modern derivatives) do not require, or have a place for, a mechanism for transfer of immunity from one clone to another.

Being able to transfer specific immunity from one clone to another contradicts the assumption of predetermined clonal specificity stated within Burnet's theory. Transfer of immunity would require the existence of a substantial pool of uncommitted $\mathrm{T}$ and $\mathrm{B}$ cell precursors. Therefore, discovery of molecules having TF activity, and the elucidation of a mechanism by which TF could transfer immunity from one clone to another, would require rethinking how the immune system is activated. In particular, it would challenge the assumption that clonal specificity is predetermined and thereby undermine the entire schema that Burnet proposed. What both Talmage (1986) and Viza (1996) pointed out is that there is no direct evidence for Burnet's assumption of predetermined clones nor has anyone devised an experiment to demonstrate predetermination. This assumption of predetermination has been accepted as a plausible consequence of experiments demonstrating that activated clones do produce a single TCR, BCR or antibody sequence after they are activated, but such experiments cannot preclude the possibility that activation itself determines clonal specificity. Equally important, recent attempts to demonstrate the existence of the $10^{12}-10^{15}$ different clones theoretically required by an organism in order to respond to any antigen have found instead less than a million different clones. While various attempts are being made to show that such measurements are simply inaccurate (by 6 to 9 orders of magnitude?!!), I choose to accept the data and suggest that, in fact, the vast majority of clones are not predetermined and that clonal specificity may be determined by antigenic challenge. TF might provide a mechanism for doing just that.

My purpose in writing this review is therefore to challenge the immunological community to consider the possibility that TF is real. If TF does indeed provoke specific $\mathrm{T}$ cell immunity as previous clinical investigators claimed, then the era of $\mathrm{T}$ cell vaccines should open before us. The fact that TF could also yield a completely novel mechanism for generating and controlling immunological activation makes $\mathrm{TF}$ a very exciting and potentially revolutionary discovery that may stimulate new discoveries in immunology that go well beyond its specific utility.

\section{What Is Transfer Factor?}

Lacking a precise molecular description of TF or a specific molecular mechanism for its action, two less precise means of characterizing it have thus far been employed. One is to describe what is known of its composition. The other is to describe what it does. 
TF is generally characterized by being a dialyzable extract of leukocytes with a molecular weight range between 3000 and 12000 daltons, most probably limited to the 3000 to 5000 range. These dialyzable extracts have only been partially purified and are known to contain several and perhaps even many molecular constituents. Since the techniques to isolate and identify the picomolar quantities of these compounds that could be isolated did not exist at the outset of $\mathrm{TF}$ research, these extracts were characterized functionally.

Functionally, TF was identified by its ability to transfer immunity from an immunized animal or person to an unimmunized one. Initially, most investigators used the appearance of delayed type hypersensitivity (DTH) reactions to demonstrate acquisition of T cell-mediated immunity. Subsequently, T cell activation assays (Rainer \& Moser, 1977), lymphocyte migration (e.g., Dunnick \& Bach, 1977; Borowsky \& Lawrence, 1979), and cytokine production (reviewed in Alvarez-Thull \& Kirkpatrick, 1996; Luna-Baca, et al, 2007) were employed. Critics of the research often charged that such measures were too non-specific to provide reliable evidence of $\mathrm{T}$ cell activation against particular antigens.

Specificity of TF was a hot-button issue from the outset, skeptics questioning how a small molecule could elicit a specific immune response. In one sense, this problem is a red herring: we know that peptide antigens of smaller molecular weights than TF (approximately 1000 to 3000 daltons for MHC-binding peptides 8 to 18 amino acids in length) are able to elicit very specific $\mathrm{T}$ and $\mathrm{B}$ cell responses, so there is no a priori reason to question whether a peptide, miRNA, or ribonucleopeptide of somewhat larger size could also induce specific immunity. One must realize, however, that many of the objections to TF were raised before the discovery of MHC I and MHC II binding specificities, and various myths existed about antigenicity itself that may have led to objections to a small molecule such as TF conferring specific immunity. For example, one widespread belief during the 1970s was that only molecules with a molecular weight over 10,000 daltons could be antigenic. In consequence, the discovery of antibodies against insulin (MW 6000) by Berson and Yalow was doubted by many experts (Yalow, 1981; Blumenthal, 2009). There is little question today that insulin is antigenic and is the main target in type 1 diabetes mellitus (Kent, et al., 2005; Narendran, et al., 2003; Schloot, et al., 1998).

Another problem that bedeviled TF research is that investigators almost universally employed dialyzable extracts from activated lymphocytes that contained several hundred compounds including a wide range of molecules known to have immunological activity of their own, such as serotonin, histamine, prostaglandins, thymic hormones, etc. (Wilson and Fudenberg, 1983). Since such molecules can attract T cells to inoculation sites, skeptics often claimed that supposedly specific DTH reactions were actually non-specific responses to monoamines and other small molecules in the preparations. Only in the best cases did investigators employ partially purified materials and it was not until the early 1980s that the specific molecular nature of TF began to emerge (Wilson and Fudenberg, 1983).

It appears that TF is a small molecule, or mixture of small molecules, including a peptide and an RNA component that can be isolated from antigen presenting cells. TF can be assayed using its ability to activate an antigen-specific response from $\mathrm{T}$ cells (Wilson and Fudenberg, 1983). TF was universally characterized as having a molecular 
weight greater than 3000 daltons and less than 12,000. TF's size seems to make it too large to be an antigen fragment (1000-3000 daltons), so it is unlikely that TF is simply soluble antigen fragments that provokes the same immune response in a naïve host as in the immunized animal. Nonetheless, one critical experiment that needs to be performed in future TF research is demonstrate definitively, or to rule out completely, the possibility that an active ingredient of TF is simply the antigen itself, or a fragment of it (Dwyer, 1996).

At present, the weight of the evidence favors TF consisting of a combination of antigen with RNA. Garvey and Campbell (1973) and Friedman (1973) demonstrated that they could transfer immunity from one animal to another with antigen-RNA complexes that were far more "immunogenic" than either the antigen or RNA alone. Thus, one common characterization of TF is as an antigen-RNA complex that produces a hyperimmune response (Lawrence, et al., 1962; Burger, Vetto \& Malley, 1972; Dressler \& Rosenfeld, 1974).

The probability that TF is composed of antigen fragments complexed with specific short RNAs is further supported by a number of experiments. Garvey, et al. $(1967 ; 1972)$ inoculated rabbits with radiolabeled keyhole limpet hemocyanin (KLH) or bovine serum albumin (BSA) and traced their excretion of the resulting antigenic fragments in urine. They found that these fragments were frequently associated with short RNA oligomers that remained bound to the antigen throughout the chromatographic processes of isolation. Moreover, the peptide-RNA complexes were highly antigenic when inoculated into additional rabbits, producing antigen-specific responses. Yuan and Campbell $(1971 ; 1972)$ further demonstrated by dissociating the peptide and RNA components that the antigenicity of the complex resided in the combination of components and not the peptide or RNA alone (see also Garvey and Campbell, 1973). Garvey and Reilly (1979) went on to show that these peptide-RNA complexes were almost certainly produced intracellularly since incubation of the antigen with cell-free rabbit serum did not produce any antigenic complex, but antigenic complexes were produced when ruptured lymphocytes or liver cells were present. These results are consistent with the observation that only lymphoid cells, or cell lysates of lymphoid cells, incubated with antigen are capable of producing immunogenic RNA-peptide complexes (Fishman and Adler, 1973; White and Johnson, 1975). Conversely, combining the RNA fraction previously isolated from random cells with random antigens in vitro, while sometimes producing RNA-antigen complexes, did not result in immunogenic complexes (Roelants and Goodman, 1969; Roelants, et al., 1971; Goodman, et al., 1973). In other words, the immunogenicity of TF appears to lie in some specific relationship between the RNA sequence and the peptide sequence involved in the formation of the complex.

Whether TF activity resides in the peptide or RNA component or their combination requires further investigation. Experiments cited above by Garvey and Campbell (Campbell, 1971; Campbell, 1972; Garvey and Campbell, 1973; Garvey and Reilly, 1979) strongly suggested that the peptide and RNA components were both required for TF activity, but subsequent experiments have demonstrated that RNA fragments can carry specific immunity that is apparently independent of any peptide or protein antigen. Hoerr, et al. (2000), for example, transcribed and purified the RNA produced by the beta-galactosidase gene, complexed it with protamine (a highly positively charged protein) to protect it from RNAases, and inoculated the complex into 
mice who subsequently produced, "Ld-restricted specific cytotoxic T lymphocytes (CTL) and production of IgG antibodies reactive against $\beta$-gal." Thus, the importance of the peptide in TF may mainly be to protect the RNA component from RNAases rather than to carry information to lymphocytes. Alternatively, the RNA fragment may protect the peptide from proteolysis, thereby increasing its antigenicity. Or both the peptide and RNA may transfer antigen-related information (see section on Mechanisms of TF Action below).

One observation consistent with a peptide-RNA complex increasing antigenic efficacy is that TF activity can be observed within 12 to 24 hours in naïve recipients. Such quick activation of $\mathrm{T}$ cell activity is never observed with antigen alone at any dose (Dwyer, 1996). So whatever the mechanism of action, specific antigen-RNA complexes appear to function differently than RNA or antigen alone.

\section{The Peptide Fragment of TF}

It is important to note that some TF researchers have argued that the peptide contained in TF preparations is not derived from the antigen. Friedman, for example, showed that lymphocyte extracts taken up to eight weeks after exposure to antigen were still highly active in stimulating a TF response and concluded therefore that antigen was not required for TF activity (Friedman, 1973). Friedman's conclusion assumed that all antigen would have disappeared from the animal by eight weeks post-inoculation, but studies by Campbell and Garvey using radiolabelled antigens found that these antigens were excreted in urine for weeks following inoculation and, more importantly, that a significant fraction of the antigen was distributed to lymph nodes where it persisted much longer (Garvey and Campbell, 1957; Garvey and Campbell, 1973). Friedman's experiments do not, therefore, negate the possibility that antigen is a critical component of TF.

Another set of experiments have also been interpreted to cast doubt on whether TF includes antigen. Borkowsky and Lawrence (1981), Petersen, et al. (1983), and Kirkpatrick (1988) each immunized animals with an antigen, isolated the TF fraction, and then used various methods to adsorb the active ingredients of the TF fraction. Each group found that addition of the antigen to the TF fraction abrogated TF activity; that passing the TF fraction through a polystyrene or dextran (Sephadex) column to which antigen had been conjugated depleted TF activity; but that passing the TF fraction through a column to which antigen-specific antibody was conjugated had no effect on TF activity. These data suggested to the researchers that TF activity is contained in a small molecule complementary to the antigen, not the peptide antigen itself. In light of the observation that TF contains RNA, however, and that the RNA may be complementary to the antigen, and also the fact that the RNA-antigen complex appears to be essential for $\mathrm{TF}$ activity, the interpretation of the experiments just summarized above becomes complicated.

For example, addition of the whole antigen to the TF fraction, or passing this fraction over a column to which antigen is bound, would elute off the RNA from the peptide fragments. RNA bound to whole antigen (as opposed to specific peptide fragments of the antigen) may not be able to activate lymphocytes (see section on Mechanisms of TF Action below) and it has previously been demonstrated that the peptides alone do not contain TF activity (see above). The RNA in the complex may also 
protect the peptide from recognition by antigen-derived antibody so that the complex passes through antibody columns relatively intact. Thus, the question of whether the RNA-peptide complex contains antigen fragments remains unresolved.

Before passing on to the characterization of the RNA component of TF, it is worth considering what the peptide component might be if it is not derived from antigen. One possibility is that it is a peptide complementary to the peptide itself, which was the view of Borkowsky and Lawrence (1981), Petersen, et al. (1983), and Kirkpatrick (1988). How and why such complementary peptides would be produced has not been explored but there is significant evidence that peptides genetically encoded by complementary strands of DNA (so-called "antisense peptides") can form short linearly complementary complexes (Blalock, 1990; Root-Bernstein and Holsworth, 1998; Siemion, et al., 2004). While some schema for the formation of an antisense peptide from a sense peptide have been hypothesized (Root-Bernstein, 1993; Nakashima and Fox, 1986; Nashimoto, 2001), these have not been adequately tested. Similarly, the function of antisense peptides as a component of TF is mysterious, the only plausible possibility being that such complementary peptides represent prototypes of the antibody hypervariable regions or $\mathrm{T}$ and B cell receptor binding sites. Their associated RNA fragments would then, presumably, encode these antibody- or TCR-binding regions.

Another possibility is that the peptide is (like the protamine in the Hoerr beta galactosidase experiment summarized above) only present to stabilize the RNA component against RNAases. This latter possibility does not appear to be consistent with Goodman's findings that random complexes of RNA with peptides to not yield antigens with TF activity (Roelants and Goodman, 1969; Roelants, et al., 1971; Goodman, et al., 1973). Thus, while investigators of TF have reported the presence of multiple peptide moieties associated with TF fractions (e.g., Burger, et al., 1979; Burger, et al., 1980; Wilson and Fudenberg, 1981; Wilson and Fudenberg, 1983; Wilson, et al., 1983), the roles of these RNA-independent peptides in TF are still unresolved. Only Kirkpatrick (2000) has isolated and sequenced any of these RNA-independent peptides, and none of the peptides he sequenced contained any TF activity. These results unfortunately illuminate little.

\section{The RNA Component of TF}

Because the RNA component of TF is also uncharacterized, many of the questions just raised about the peptide component remain unresolved for the RNA component. There seems to be little doubt that TF incorporates short sequences of RNA (Mannick \& Egdahl, 1964; Wang and Mannick, 1968; Friedman, 1973; Garvey and Campbell, 1973; Gottlieb, et al., 1973). Some early TF investigators (e.g., Sabbadini and Sehon, 1967; Paque and Dray, 1970; Satz, et al., 1980) claimed that this RNA component was sufficient to transfer antigen-specific immunity, but in these experiments it was assumed, rather than proven, that the purified RNA fractions did not contain peptides. Since the antigen-RNA complex is stable through various purification procedures (Garvey, et al.,1967; Garvey, et al.,1972; Garvey and Campbell, 1973), merely isolating the RNA fraction would not preclude the presence of associated peptide. In fact, Friedman et al. (1965) and Askonas and Rhodes (1965) had already demonstrated in 1965 the presence of peptide antigen in what was otherwise thought to be "pure" RNA 
fractions. Thus, the conclusion that the RNA component alone contains the TF activity must be left, like so much about TF, in abeyance of further tests.

Suffice it to say that most investigators of TF function have assigned its activity to a combination of both the RNA and peptide components. For example, Fudenberg (Wilson and Fudenberg, 1981; Wilson, Paddock \& Fudenberg, 1981; Wilson, Paddock \& Fudenberg, 1982; Wilson and Fudenberg, 1983) proposed a model of TF consisting of a peptide conjugated to a diribonucleotide. Other investigators have proposed that the TF consists either of a ribonucleoprotein (RNP) or separate RNA sequence significantly longer than a diribonucleotide. Rifkind (Rifkind, et al., 1976; 1977) reported that treating TF isolates with RNAase resulted in release of a peptide or RNP that lost TF activity, suggesting that RNA was a critical component of specific TF. Similarly, Gottlieb showed that TF preparations contain short sequences of RNA, or what we might today call microRNAs, that are complementary to the antigen (Gottlieb, et al., 1973; Waldman and Gottlieb, 1975). Because the RNA was stable, it was assumed that it was in a double stranded form (Gottlieb, et al., 1973; Dressler and Rosenfeld, 1974; Waldman and Gottlieb, 1975; Burger, et al., 1979; Wilson, et al., 1983), but it is equally likely that the stability is induced by complexation with the peptide component. Another possibility is that the peptide binds specifically to double-stranded RNAs.

Complexation of RNA with peptide assumes some type of molecular complementarity between the two, the function of which is as yet unclear. As noted above, one possibility is that the peptide and RNA protect each other against proteases and/or RNAases, and there is certainly evidence to support the extraordinary stability of TF. For example, several investigators have demonstrated that TF can be delivered orally without loss of activity (Visa, 1985; Kirkpatrick, et al., 1995; Kirkpatrick, 1996; Viza, et al., 1996; Masi, et al., 1996). But beyond stabilizing TF in order to permit its transfer from an activated lymphocyte to unactivated ones, the question of what information TF is carrying remains unclear. Do either the RNA or the peptide moieties, or both, carry information to other lymphocytes, what does this information "say", and how is it used?

Surprisingly, even in the absence of knowing the sequences of the peptides and RNAs comprising TF complexes, it is possible to infer some conclusions about what information TF carries from studies of the specificity of its effects.

\section{How Specific is TF Activity?}

TF research has, since its inception, focused largely on two problems besides the physicochemical nature of TF. One problem was how specific TF activity is; the other problem was how effective TF is in clinical settings. I shall not address the latter issue, first of all because it has recently been reviewed by Viza, et al. (2013) and also because I have found no double blind clinical studies and only two non-blinded studies involving appropriate controls (placebo or in comparison with other available treatment options) with treatment reversal. One controlled study involved only seven hepatitis-infected individuals and yielded negative results (Sodomann, et al, 1979). The other involved fourteen patients treated for AIDS-related cryptosporidiosis, which yielded very significantly positive results (McMeeking, et al., 1990). The remaining studies, while almost uniformly reporting positive results, do not appear to me to be sufficiently robust to draw useful conclusions. Unfortunately, TF has been used to treat an extraordinarily wide range of diseases using materials prepared according to an almost equally wide 
range of methodologies so that it is almost impossible to compare clinical results. Standardization of TF purification procedures (or its synthetic manufacture) will have to be one of the main goals of any future research, assuming animal experimentation warrants it.

Laboratory studies of TF activity are generally of much higher quality than clinical studies, though the problem of a multiplicity of isolation procedures is an issue here as well. TF experts spent a great deal of time and effort between 1970 and 1990 demonstrating that TF elicited by well-defined antigens transferred immunity that was limited to an immune response to the eliciting antigen. Friedman (1973) showed that TF induced by Shigella lipopolysaccharides produced immunity completely distinguishable from that induced against sheep red blood cells or Salmonella vaccine. Gottleib, et al., (1973) demonstrated that TF raised against the L-copolymer of glycine, alanine and threonine (GAT) did not induce immunity against D-copolymer of GAT, and vice versa. Zuckerman, et al. (1974) demonstrated similarly that TF derived from tuberculininoculated human subjects transferred tuberculin sensitivity to naïve recipients, but did not induce immunity to keyhole limpet hemocyanin (KLH). Human subjects inoculated with KLH produced TF that could transfer KLH sensitivity to naïve subjects, but not tuberculin sensitivity. These results were, however, challenged by Salaman (1978) who claimed to find that TF from tuberculin-positive patients (but oddly, no other patients) stimulated general lymphocyte activation to any antigen.

Perhaps the most definitive set of tests of TF specificity were run by Tsang and Fudenberg (1986). They compared responses to TF derived from osteosarcoma associated antigens, fibrosarcoma associated antigens, and purified protein derivative (PPD) from mycobacteria and tested them not only against each other, but a wide variety of additional proteins as well. The TF-mediated immunity was in all cases extremely specific, with no observable cross-reactivity between the antigens tested. Also, Kirkpatrick (1993) demonstrated that murine TF raised against ovalbumin, cytochrome c, ferritin, horse radish peroxidase, and a random copolymer of glutamic acid, lysine and alanine each induced immunity in recipients that was not cross-reactive with the other antigens. In sum, studies of the specificity of the immunity transferred by TF from one lymphocyte to others generally suggest that an antigen-specific message is involved.

One unusual aspect of the specificity studies is that TF from one species (cow) was reported to be fully functional in other species (human beings) (McMeeking, et al., 1990). This finding suggests that whatever message TF carries is not species specific and therefore opens up the possibility of genetically engineering the production of TF against specific antigens.

\section{How Transfer Factor Challenges the Standard Model of Immunological Activation}

Assuming TF exists and has the kinds of properties that investigators have associated with it, then the consequences for immunological theory are potentially revolutionary. Begin by considering the standard model of how the immune system is activated in the presence of an antigen. The standard model is based on Burnet's clonal selection theory, in which the immune system generates all possible variants of $\mathrm{T}$ cell receptors (TCR) during early development and then eliminates or tolerizes self-reactive clones to leave the set of clones capable of responding to any foreign antigen. When an antigen presenting cell (APC) expresses a fragment of a foreign antigen on its cell surface 
in the presence of major histocompatibility complex (MHC) and encounters a $\mathrm{T}$ cell bearing the appropriate TCR, this T cell is induced to clone itself, initiating an active immune response against the antigen. The critical features of this standard model for current purposes are, first, that all clones are pre-programmed to respond to only a very limited range of antigens, and secondly, that activation of T cells by APC is mediated purely by a physical interaction between MHC and TCR in the presence of a specific antigen; no chemical entity need be transferred from APC to T cells or vice versa.

Enter transfer factor. TF's size makes it difficult to understand how it can stimulate an immune response in a naïve host within the framework of the standard model. To begin with, there should be only one clone (or at most, a very limited range of clones) that might be activated by any particular TF, and this should be the same clone (or set of clones) activated by the original antigen. Thus, of what use is TF? And secondly, there should be no set of naïve clones that could be programmed (or reprogrammed) by whatever message TF carries. So again, of what use is TF?

The standard model is, however, incomplete. Independent of research on TF, there is a substantial body of research showing that antigen, sometimes along with MHC, is transferred from APC to T cells (Bona, et al., 1973; Arnold, et al., 1997; Arnold and Mannie, 1999; Patel, et al., 1999; Huang, et al., 1999; Hwang, et al., 2000; Hwang and Sprent, 2001; Hudrisier, et al., 2001; reviewed in Hudrisier and Bongrand, 2002). MHCassociated antigen is also taken up by B cells (Lanzavecchia, 1990; Batista and Neuberger, 2000; Batista, et al., 2001). While the activation of T cell receptors (TCR) or $\mathrm{B}$ cell receptors (BCR) by binding of processed antigen in the presence of $\mathrm{MHC}$ has a clear function in activating pre-programmed $\mathrm{T}$ and $\mathrm{B}$ cells, there is no clear rationale within modern immunological theory for the actual transfer of antigen from APCs to T or $\mathrm{B}$ cells. What do the $\mathrm{T}$ and $\mathrm{B}$ cells $d o$ with the antigen if it has already performed its function of activating their receptors?

I propose that antigen transfer and TF are related processes in an antigen-specific, induced transformation of uncommitted $\mathrm{T}$ and $\mathrm{B}$ cells. This possibility has been overlooked because it is at odds with current immunological dogma, which states that there are no such uncommitted cells. But the dogma is almost certainly wrong. Uncommitted lymphocytes make up a significant proportion of the lymphocyte population at any given time. Three types of experiments have demonstrated the existence of such an uncommitted population. The first type of experiments involved the binding of radiolabeled or otherwise detectable antigens such as enzymes to lymphocyte and demonstrated (depending on the criteria used for specificity) that between 1 in 50 and 1 in 1500 lymphocytes specifically bound any given antigen (Naor and Salitzneau, 1967; Dwyer and Mackay,1972; Haywood and Soothill, 1972; Cooper, et al., 1972; UrbainVansanten, et al., 1974; De Luca, et al., 1974). Similarly, limiting dilution experiments also have provided consistent evidence that randomly selected sets of between 50 and 1000 peripheral blood lymphocytes can uniformly be activated to produce specific antibody to any antigen (McCarthy and Dutton, 1975; Salaman, 1978; Stein et al., 1983; Dosch, et al., 1985; Kindred and Corley,1978; Dozmorov, et al.,1996; Dozmorov, et al., 2000). Additional studies of specific binding of antigens to neonatal lymphocytes similarly concluded that there is no evidence of precommitment of T or B cells during ontogeny as predicted by the clonal selection theory (Miller, et al., 1971; Hayward, A. R. and Soothill, 1972; Decker, et al., 1974; Urbain-Vansanten, et al., 1974; Stein, et al., 
1983). Finally, experiments involving tadpoles, which have only about 10,000 total lymphocytes, have failed to identify any antigen against which a specific antibody response cannot be induced (Du Pasquier, 1976). It is difficult to imagine how a mere 10,000 lymphocytes can respond to any random set of antigens if the lymphocytes are precommitted.

We must therefore seriously consider the likelihood that lymphocytes are not precommitted and that a mechanism exists by which antigens specify TCR, BCR and antibody specificity only after exposure to specific antigens. In this event, transfer factor could be the means by which activated cells commit other cells to the same antigen specificity.

\section{Is TF Part of a Eukaryotic CRISPR-Cas-Like System?}

How might such antigen transfer via a TF pathway induce lymphocyte commitment? One possibility is that TF is part of a eukaryotic system that functions analogously to the bacterial CRISPR-Cas system. CRISPR (clustered regularly interspaced short palindromic repeats) are viral gene sequences inserted into bacterial genomes after exposure to the viruses. CRISPR-associated (Cas) proteins are enzymes that use CRISPR sequences as templates for specific strands of DNA that are complementary to the CRISPR sequence. In short, the CRISPR-Cas system functions as a primitive immune system essentially by keeping a record of virus sequences that bacteria have encountered so that complementary sequences to these viruses can be generated rapidly in response to any future infection (Barrangou, 2015; Barrangou, et al., 2007; Marraffini and Sontheimer, 2008). One can easily imagine a similar system having evolved in eukaryotes in which antigens from microbes are transferred from monocytes to $\mathrm{T}$ and $\mathrm{B}$ cells to be incorporated into the hypervariable regions of the genes encoding $\mathrm{T}$ and $\mathrm{B}$ cell receptors and antibodies so that these proteins can act as complementary sequences to each antigen. In this case, instead of accumulating many such antigen repeats within a single genome, as bacteria do, eukaryotic immune systems have evolved a system in which each $\mathrm{T}$ or $\mathrm{B}$ cell clone becomes specialized to produce a response to a single antigen.

Various features of TF suggest involvement in such a CRISPR-Cas-like system. The small size of TF provides one clue. Dressler and Rosenfeld (1974) argued that, "The transfer factor is too small (it can pass through a dialysis membrane) to code for the specific proteins involved in an immune response." Their statement, however, preceded the recognition that antibodies, $\mathrm{B}$ cell receptors and $\mathrm{T}$ cell receptors are composed of diverse genetic elements that include a hypervariable region. This hypervariable region is very short, consisting of only a dozen or so amino acids thereby matching the length of antigens generally presented by human leukocyte antigen proteins to $\mathrm{T}$ and $\mathrm{B}$ cell receptors. Current theory proposes that this hypervariable region is generated by random insertion or deletion of codons by RAG1 and RAG2 proteins during the integration of the diverse genetic elements encoding the antibody or receptor. The specific mechanism by which the immune system produces such random genetic insertions and deletions has never been identified, which leaves open other possibilities. What if, for example, the RNA moiety associated with TF encodes the hypervariable region of antibodies, TCR and BCR? What if RAG1-RAG2 use TF as a template? Basten and Edwards (1976) reported, for example, that TF isolates from mice contain fragments of I-region gene 
products, which is to say, hypervariable region sequences. Are these fragments breakdown products of antibodies, BCR and TCR? Or, conversely, might they be the building blocks of their hypervariable regions? This possibility would be consistent with the observation that only lymphoid cells are able to produce RNA-antigen complexes. Might the RNA component in TF therefore be hypervariable region-encoding (HRE) RNAs.

Another possibility mentioned above, which could work either with a CRISPRCas-like system or represent a novel and independent evolution, is that antigens are reverse translated into RNA sequences (Root-Bernstein, 1983; Nakashima and Fox, 1986; Nashimoto, 2001), which then encode the hypervariable regions of antibodies or TCR and BCR binding sites. Depending on whether the TF is associated with hapten or antigen, it would activate either BCR or TCR (Gottlieb, et al., 1973). Once again, such a mechanism would result in a CRISPR-Cas like gene product, in this case inserted preferentially into TCR, BCR and antibody hypervariable region genes.

A skeptic would rightly point out that there is little evidence for the mechanisms that I have just proposed and, moreover, reverse translation contradicts the "Central Dogma of Molecular Biology" (Crick, 1970). Reasons for rejecting the Dogma's prohibition of reverse translation have been addressed by several investigators (RootBernstein, 1983; Nakashima and Fox, 1986; Nashimoto, 2001) and essentially amount to the fact that the prohibition against reverse translation is based on lack of evidence. Crick, in fact, was very clear that he named the Dogma a "dogma" because it had to be accepted on faith because a negative statement cannot be tested. Faith is not a valid basis for scientific work! Until someone seriously looks for reverse translation, it would be a mistake to assume that it cannot occur and the mysteries of TF provide one arena in which reverse translation might have value to living organisms.

Completely independent of Central Dogma issues, it remains a fact that antigen, whether alone or as an antigen-RNA complex (TF), is transferred from APC to T and B cells and there must be some reason for such a transfer mechanism to exist or it would not persist. Finding out what the antigen (or TF complex) does inside T and B cells will yield some type of surprise and that, after all, is the purpose of research.

With regard to such surprises, it is also important to realize that lymphocytes behave in ways that other cells in the body do not, altering their genetic organization to respond to novel antigens. The experiments cited above with regard to the production of RNA-antigen complexes clearly suggest that whatever mechanisms are involved in this process are unique to lymphoid cells (Yuan and Campbell (1971; Yuan and Campbell, 1972; Garvey and Campbell, 1973; Garvey and Reilly, 1979; Fishman and Adler, 1973; White and Johnson, 1975; Roelants and Goodman, 1969; Roelants, et al., 1971; Goodman, et al., 1973). Thus, while it is certainly a stretch at present to assert that lymphoid cells have the capability of producing novel RNAs in response to antigens, since we already know that bacteria can do this in response to viral antigens, it would seem to be much less of a stretch to assert that the TF is a mechanism that has evolved to make sure that TCR, BCR and antibodies all respond to any particular antigen by exactly matching their molecular responses than to imagine, as the current theory would have it, that $\mathrm{T}$ cells, B cells and plasma cells produce matching responses completely randomly by some uncharacterized mechanism. 


\section{New Tests of TF}

For the many reasons discussed above, I believe that it is well worth exploring whether TF exists and has the properties ascribed to it by previous investigators. In order to do so, new approaches are required.

To begin with, if a CRISPR-Cas-like mechanism suggested above is responsible for TCR, BCR and antibody hypervariability, then just as sequences in bacteria mimic the viruses to which the bacteria is immunized against, so should the hypervariable regions of TCR, BCR and antibodies mimic the microbial sequences against which they protect. Notably, several studies have documented that TCR do mimic HIV and other microbial sequences at frequencies far above what would be expected from a random mechanism of sequence generation (De Groot, et al., 2014; Moise, et al., 2014; Moise, et al., 2016; Root-Bernstein, 2016; Root-Bernstein, 2017; Swiatzcak and Tauber, 2018). This phenomenon of TCR mimicking antigens (and vice versa) is very new and very limited at present and in need to much larger studies with better controls, but the existing results are surprising enough to merit such effort. Moreover, no one has yet looked at whether BCR and antibody hypervariable regions similarly mimic antigen sequences, which represents a novel prediction and extension of the existing TCR data.

If such data are forthcoming, an obvious follow-up would be to search for a CRISPR-Cas-like mechanism within TCR and BCR capable of generating hypervariable regions for these proteins. The possibility that $\mathrm{TF}$ plays a role in such a mechanism is warranted by the data summarized above.

Another approach would be to develop animal models involving T-cell mediated immunity that can be induced by simple, molecularly defined antigens are required. One possibility might be experimental allergic encephalomyelitis (EAE), a T-cell mediated autoimmune disease resulting in ascending paralysis that can be induced in guinea pigs using a nonapeptide derived from myelin basic protein in combination with the minimal adjuvant, muramyl dipeptide. The simplicity and defined nature of the antigen and adjuvant would make it possible to identify the presence of either component within TF isolates thereby addressing the issue of whether TF contains antigen (or adjuvant, for that matter). Moreover, the sequence relationship, if any, between the peptide and the RNA components of TF will easily become apparent by using such a well-defined antigen.

The use of a T-cell mediated disease model such as EAE has further benefits as well involving its transferability. One of the most important claims about TF is that it is capable of transferring T-cell mediated immunity. EAE can be transferred from an affected animal to an unaffected animal by means of adoptive transfer of T cells. If TF has the functions that it is supposed to have, then TF isolated from EAE animals should be able to produce EAE in healthy recipients. Moreover, it has proven possible to prevent EAE by inoculating animals with the peptide antigen some weeks prior to receiving an encephalotigenic peptide-adjuvant combination. It should therefore similarly be possible to prevent EAE by inoculating one animal with the peptide antigen and using TF from that animal to activate $T$ cell protection in a recipient animal. Similarly, the peptide antigen can be used to down-regulate EAE after it has been elicited, so that TF from a peptide-inoculated animal might have a similarly therapeutic effect.

Most importantly, technologies developed since 1990 make it possible to identify and track the production of TF by the immune system. Mass spectrometry techniques now make it possible to identify with great detail even femtomoles of peptides and 
RNAs. Equally importantly, peptide and RNA synthesis have both become readily available so that once the components of TF associated with any particular antigen have been elucidated, these can be synthesized and variants made that can be used to investigate the sequence specificity of the components. Optimization of TF might then lead to the manufacture of T-cell vaccines and a new era in understanding immune function.

\section{Conclusion: A Few Notes on the History and Philosophy of Discovery}

In concluding, it is worth placing TF research within a more general framework of the history and philosophy of biomedical discovery. To begin with, while skepticism is one of the most important of scientific tools, I believe that we should doubt most those results that best fit our preconceptions and take most seriously those that challenge them. TF certainly challenges many aspects of modern immunology and molecular biology. On the other hand, its effects have been reported so often by so many diverse groups that to ignore its possible existence seems obtuse. To investigate only those phenomena that fit our expectations is to turn out back on discover (Kuhn, 1959). Precisely for this reason, we must take it most seriously and most rigorously test TF. If TF does not exist, then it is time that it be put to rest once and for all. If TF truly does exist, the implications for understanding how the immune system works, and harnessing that understanding to Tcell mediated diseases, will be enormous. Either way, we will learn something fundamental about immune function.

\section{ACKNOWLEDGEMENTS}

The writing of this manuscript was supported by a prize from an InnoCentive Challenge \#9780464 - Extraordinary and Unorthodox Philanthropy, January 2011.

\section{REFERENCES}

Alvarez-Thull L, Kirkpatrick CH. 1996. Profiles of cytokine production in recipients of transfer factors. Biotherapy 9: 55-59.

Arala-Chaves M, Ramos MTF and Rosado RMF. 1974. Evidence for prompt and intense constitution of cell-mediated immunity by means of transfer factor in a case of complex immune deficiency. Cell. Immunol. 12:160.

Askonas BA., Rhodes JM. 1965. Immunogenicity of antigen-containing RNA preparation from macrophages. Nature London 205: 470.

Barrangou R. 2015. The roles of CRISPR-Cas systems in adaptive immunity and beyond. Current Opinion in Immunology. 32: 36-41. doi:10.1016/j.coi.2014.12.008

Barrangou R, Fremaux C, Deveau H, Richards M, Boyaval P, Moineau S, et al. 2007. CRISPR provides acquired resistance against viruses in prokaryotes. Science. 315 (5819): 1709-12. doi:10.1126/science.1138140. PMID 17379808. 
Basten A, Croft S, Edwards J (1976) In: Ascher MS, Gottlieb AA, Kirkpatrick CH (eds) Transfer factor: basic properties and clinical application. Academic Press, New York, 175.

Blumenthal S. (2009). The insulin immunoassay after 50 years, A reassessment. Persp Biol Med 52: 343-354. DOI, 10.1353/pbm.0.0091

Borysov VA, Cheusova ZV, Molozhava OS. 1998. [The adjuvant and specific activity of transfer factors to Candida albicans antigens]. Fiziol Zh. 44(4):3-9.

Burger, D. R., Vetto, R. M. \& Malley, A. (1972) Transfer factor from guinea pigs sensitive to dinitrochlorobenzene: absence of superantigen properties. Science 175, 14731475.

Burger DR, Vandenbark AA, Dunnick W, Kraybill W, Daves GD, Vetto RM. 1979. Human transfer factor: Structural properties suggested by HPRP chromatography and enzymatic sensitivities. J. Immnology 122: 1091-1098.

Burger DR, Wampler P, Vandenbark AA \& Vetto RM. 1979. A structural model for human transfer factor suggested by enzymatic susceptibilities. In: Immune Regulators in Transfer Factors. New York: Academic Press, pp. 377-85.

Burnet FM. 1974. Transfer factor - a theoretical discussion. J Allerg Clin Immunol 54(1): $1-13$.

Cook ND. The case for reverse translation. J Theor Biol. 1977 Jan 7;64(1):113-35.

Cooper MG, Ada GL, Langman RE. The incidence of hemocyanin-binding cells in hemocyanin-tolerant rats. Cell Immunol. 1972 Jul;4(3):289-303.

Craig R. 1981. The theoretical possibility of reverse translation of proteins into genes. J Theor Biol. 88(4):757-60.

De Carvalho S, Schultz RD. An information transfer hypothesis of the immune response based on the genetic code. Oncology. 1971;25(4):297-312.

Decker JM, Clarke J, Bradley LM, Miller A, Sercarz EE. 1974. Presence of antigenbinding cells for five diverse antigens at the onset of lymphoid development: lack of evidence for somatic diversification during ontogeny.J Immunol. 113(6):1823-33.

De Groot AS, Moise L, Liu R, Gutierrez AH, Tassone R, Bailey-Kellogg C, Martin W. 2014. Immune camouflage: Relevance to vaccines and human immunology. Hum. Vaccin. Immunother. 10, 3570-3575. 
De Luca D, Decker J, Miller A, Sercarz E. 1974. Antigen binding to lymphoid cells from unimmunized mice: high frequency of beta-galactosidase binding cells at optimal conditions. Cell Immunol. 10(1):1-18

De Vinci C, Pizza G, Cuzzocrea D, Menniti D, Aiello E, Maver P, Corrado G, Romagnoli P, Dragoni E, LoConte G, Riolo U, Masi M, Severini G, Fornarola V, Viza D. 1996. Use of transfer factor for the treatment of recurrent non-bacterial female cystitis (NBRC): a preliminary report. Biotherapy 9(1-3):133-8.

Dosch HM, Lam P, Guerin D. 1985. Differential regulation of activation, clonal expansion, and antibody secretion in human B cells. J Immunol. 1985 Dec;135(6):380816.

Dozmorov IM, Lutsenko GV, Sidorov LA, Miller RA. 1996. Analysis of cellular interactions in limiting dilution cultures. J Immunol Methods.189(2):183-96.

Dressler D, Rosenfeld S. 1974. On the chemical nature of transfer factor. Proc Natl Acad Sci USA 71(11): 4429-4434.

Dunnick WA, Bach FH. 1977. Specificity and structural analysis of a guinea pig transferfactor like activity. J Immunol 118(6): 1944-1950.

Du Pasquier L. 1976. [The acquisition of antibody diversity studied in anuran amphibians (author's transl)]. Ann Immunol (Paris). 127(3-4):467-74

Dwyer JM, Mackay IR. Validation of autoradiography for recognition of antigen-binding lymphocytes in blood and lymphoid tissues. Quantitation and specificity of binding. Clin Exp Immunol. 1972 Apr;10(4):581-97.

Fabre RA, Pérez TM, Aguilar LD, Rangel MJ, Estrada-Garcìa I, Hernández-Pando R, Estrada Parra S. 2004. Transfer factors as immunotherapy and supplement of chemotherapy in experimental pulmonary tuberculosis. Clin Exp Immunol 136(2):21523.

Fernandez-Ortega C, Dubed M, Ruibal O, Vilarrubia OL, Menendez san Pedro JC, Navea L, Ojeda M, Arana MJ. 1996. Inhibition of in vitro HIV infection by dialysable leucocyte extracts. Biotherapy 9: 33-40.

Fishman M, Adler FL. The formation of immunogenic RNA-antigen complexes in a cellfree system. Cell Immunol. 1973 Aug;8(2):221-34.

Friedman HP, Stavitsk AB, Solomon YJM. 1965. Induction in vitro of antibodies to phage R: antigens in the RNA extract employed. Annals New York Academy of Sciences 149: 1106.

Friedman H. 1973. Immunogenic RNA during immunity and tolerance. Ann N Y Acad Sci 207: 178-199. 
Fudenberg H, Pizza G. 1994. Transfer factor 1993: New frontiers. Progress in Drug Res 42: 309-400.

Garvey, J. S. and Campbell, D. H,, 1957. The retention of S35-labelled bovine serum albumin in normal and immunized rabbit liver tissue. J. Exp. Med. 105, 361-372.

Garvey JS, Campbell DH, Das ML. Urinary excretion of foreign antigens and RNA following primary and secondary injections of antigens. J Exp Med. 1967 Jan $1 ; 125(1): 111-26$.

Garvey JS, Rinderknecht H, Weliky BG, Campbell DH. The use of a nucleopeptide fraction from injected rabbits to study the nature of antigen fragment-RNA association. Immunochemistry. 1972 Feb;9(2):187-206.

Garvey JS, Campbell DH. 1973. Characterization of RNA-antigen complexes. Ann N Y Acad Sci 207: 258-278.

Garvey JS, Reilly EB. Studies of antigen-RNA and immunity. Mol Cell Biochem. 1979 Mar 5;24(1):45-62.

Goodman JW, Roelants GE, Byers VS. RNA-antigen complexes: mechanism of formation and the testing of a postulated mode of action. Ann N Y Acad Sci. 1973 May 31;207:288-300.

Gottlieb AA, Schwartz RH, Kudva SA, Waldman SR. 1973. The nature of antigenribonucleoprotein complexes. Ann N Y Acad Scis. 207: 279-287.

Gottlieb AA, Foster LF \& Waldman SR. 1973. What is transfer factor? Lancet 2: 82223.

Haurowitz F. The role of RNA in antibody formation. Historical perspectives. Ann N Y Acad Sci. 1973 May 31;207:8-16.

Haurowitz F. The problem of antibody diversity. Immunodifferentiation versus somatic mutation. Immunochemistry. 1973 Nov;11(10):775-83.

Hayward, A. R. and Soothill, J. F. 1972. CIBA Symposium : Ontogeny of Acquired Immunity, pp. 261-273. Associated Scientific Publishers, Amsterdam.

Hoerr I, Obst R, Rammensee HG, Jung G. In vivo application of RNA leads to induction of specific cytotoxic T lymphocytes and antibodies. Eur J Immunol. 2000 Jan;30(1):1-7.

Kent SC, Chen Y, Bregoll L, Clemmings SM, Kenyon NS, Ricordi C, Hering BJ, Hafler DA. Expanded T cells from pancreatic lymph nodes of type 1 diabetic subjects recognize an insulin epitope. Nature 2005; 435: 224-228. 
Kindred B, Corley RB. 1978. Specificity of helper T cells for different antigens. Eur J Immunol. 8(1):67-71.

Kirkpatrick CH. 1988. Transfer factor. J Allerg C1 81: 803-812.

Kirkpatrick CH. 1993. Structural nature and functions of transfer factors. Ann N Y Acad Sci :362-368.

Kirkpatrick CH. 1996. Activities and characteristics of transfer factors. Biotherapy. 9(13):13-6.

Kirkpatrick CH. 2000. Transfer factors: Identification of conserved sequences in transfer factor molecules. Molecular Medicine 6: 332-341.

Kirkpatrick CH, Hamad AR, Morton LC. 1995. Murine transfer factors: Dose response relationships and routes of administration. Cell Immunol 164: 203-206.

Kirkpatrick CH, Smith TR. 1976. Serial transfer of delayed hypersensitivity with dialyzable transfer factor. Cellular Immunology 27: 323-327.

Kirkpatrick CH, Rozzo SJ, Mascali JJ, Merryman CF. 1985. Murine transfer factor. II. Transfer of delayed hypersensitivity to synthetic antigens. J. Immunol. 134: 1723-1727.

Kirkpatrick CH, Rozzo SJ, Mascali JJ. 1985. Murine transfer factor. III. Specific interactions between transfer factor and antigen. J. Immunol. 135: 4027-4033.

Lawrence HS. 1955. The transfer in humans of delayed skin sensitivity to streptococcal M substance and to tuberculin with disrupted leucocytes. J Clin Inv 34: 219-32.

Lawrence, H. S., Rapaport, F. T., Converse, J. M. \& Tillett, W. S. (1962) J. Clin. Invest. 39, 185-198.

Lawrence HS. 1969. Transfer factor. Adv Immunol. 11:195-266.

Lawrence HS. 1974 Transfer factor in cellular immunity. The Harvey Lectures, Series 68: 239-350.

Li C, Huang L, Wang Y, Li X, Liang S, Zheng Y. 2010. Preparation and properties of the specific anti-influenza virus transfer factor. Head \& Face Medicine 2010, 6: 22-29.

Liubchenko TA, Holeva OH, Kholodna LS, Smirnov VV, Vershyhora AIu. Mikrobiol Z. 1997. [The biological activity of the transfer factor induced by bacterial antigens]. 59(5):83-100.

Luna-Baca GA, Linares M, Santacruz-Valdes C, Aquilar-Velazquez G, Chavez R, PerezTapia M, Estrad-Garcia I, Estrada-Parra S, Jimenez-Martinez MC. 2007. Immunological 
study of patients with herpetic stromal keratitis treated with dialyzable leukocyte extracts. 13th International Congress of Immunology - ICI, pp. 67-71.

Mannick JA, Egdahl RH (1964) Transfer of heightened immunity to skin homografts by lymphoid RNA. J Clin Invest 43:2166

Marraffini LA, Sontheimer EJ. 2008. CRISPR interference limits horizontal gene transfer in staphylococci by targeting DNA. Science. 322 (5909): 1843-5.

doi:10.1126/science. 1165771

Masi M, De Vinci C, Baricordi OR. 1996. Transfer factor in chronic mucocutenous candidiasis. Biotherapy 9: 97-103.

McCarthy MM, Dutton RW. 1975. The humoral response of mouse spleen cells to two types of sheep erythrocytes. II. Evidence for gene expression in the B lymphocyte. $\mathrm{J}$ Immunol. 115(5):1322-6.

McMeeking A, Borkowsky W, Klesius H, Bonk S, Holzman HS, Lawrence HS. 1990. A controlled trial of bovine dialyzable leukocyte extract for cryptosporidiosis in patients with AIDS. J Infect Dis 161: 108-112.

Mekler LB. [Mechanism determining the variability of the immunologic specificity spectrum of antibodies and other immunoglobulins (theory)]. Biofizika. 1977 NovDec;22(6):1129-39.

Miller A, De Luca D, Decker J, Ezzell R, Sercarz EE. Specific binding of antigen to lymphocytes. Evidence for lack of unispecificity in antigen-binding cells. Am J Pathol. 1971 Nov;65(2):451-65

Moise L, Terry F, Gutierrez AH., Tassone R, Losikoff P, Gregory SH, Bailey-Kellogg C, Martin WD, de Groot AS. 2014. Smarter vaccine design will circumvent regulatory T cell-mediated evasion in chronic HIV and HCV infection. Front. Microbiol. 2014, 5, 502.

Moise L, Beseme S, Tassone R, Liu R, Kibria F, Terry F, Martin W, de Groot AS. 2016. T cell epitope redundancy: Cross-conservation of the TCR face between pathogens and self and its implications for vaccines and autoimmunity. Expert Rev. Vaccines 15, 607617.

Nakashima T, Fox SW. 1986. Experiments on reverse translation. Orig Life Evol Biosph 16 (3-4): 476.

Naor D, Sulitzneau D. 1967. Binding of radioiodinated bovine serum albumin to mouse spleen cells. Nature. 214(5089):687-8. 
Narendran P, Williams AJ, Elsegood K, Leech NJ, Dayan CM. Humoral and cellular immune responses to proinsulin in adults with newly diagnosed type 1 diabetes. Diabetes Metab Res Rev 2003 Jan-Feb; 19(1): 52-9.

Nashimoto M. The RNA/protein symmetry hypothesis: experimental support for reverse translation of primitive proteins. J Theor Biol. 2001 Mar 21;209(2):181-7.

Petersen EA, Greenberg LE, Manzara T, Rozzo S J, Kirkpatrick CH (1983) Selective removal of transfer factor activity with antigen. In: Kirkpatrick EH, Burger DR, Lawrence HS (eds) Immunobiology of Transfer Factor. Academic Press, New York, pp. $65-74$.

Pineda B, Estrada-Parra S, Pedraza-Medina B, Rodriguez-Ropon A, Pérez R, Arrieta O. 2005. Interstitial transfer factor as adjuvant immunotherapy for experimental glioma. $\mathrm{J}$ Exp Clin Cancer Res. 24(4):575-83.

Pizza G, De Vinci C, Fornarola V, Palareti A, Baricordi O, Viza D. 1996. In vitro studies during long-term oral administration of specific transfer factor. Biotherapy. 9(1-3):17585 .

Rainer H, Moser K. 1977. In vitro-Untersuchungen mit menschlichem Transferfaktor. Blut 34: 471-478.

Rifkind D, Frey JA, Peterson EA, Dinowitz M (1977) Transfer of delayed hypersensitivity in mice to microbial antigens with dialyzable transfer factor. Infect lmmun 16:258

Rifkind D, Frey JA, Peterson EA, Dinowitz M (1976) Delayed hypersensitivity to fungal antigens in mice. II. Molecular classes in immunogenic RNA extracts that transfer delayed hypersensitivity. J Infect Dis 133:523

Roelants GE, Goodman JW. The chemical nature of macrophage RNA-antigen complexes and their relevance to immune induction. J Exp Med. 1969 Sep 1;130(3):55774.

Roelants GE, Goodman JW, McDevitt HO. Binding of a polypeptide antigen to ribonucleic acid from macrophage, HeLa and Escherichia coli cells. J Immunol. 1971 May;106(5):1222-6.

Root-Bernstein, R. S. Protein Replication by Amino Acid Pairing, J. theor. Biol. $\underline{100}$ (1983), 99-106.

Root-Bernstein R. 2016. Autoimmunity and the microbiome: T-cell receptor mimicry of "self" and microbial antigens mediates self tolerance in holobionts: The concepts of "holoimmunity" (TcR-mediated tolerance for the holobiont) and "holoautoimmunity" 
(loss of tolerance for the holobiont) are introduced. Bioessays.38(11):1068-1083. doi: 10.1002/bies.201600083.

Root-Bernstein R. 2017. Human Immunodeficiency Virus Proteins Mimic Human T Cell Receptors Inducing Cross-Reactive Antibodies. Int J Mol Sci. 18(10). pii: E2091. doi: 10.3390/ijms18102091.

Root-Bernstein, R.S.; Holsworth, D.D. Antisense peptides: a critical mini-review. ,J Theor, Biol. 1998, 190(2): 107-19.

Rozzo SJ, Kirkpatrick CH. 1992. Purification of transfer factors. Molec. Immunol. 29: $167-182$.

Sabbadini E, Sehon AH (1967) Acceleration of allograft rejection induced by RNA from sensitized donors, Int Arch Allergy Appl Immunol 32:55

Salaman MR. (1978) An investigation into the antigen-specificity of transfer factor in its stimulatory action on lymphocyte transformation. Immunology. 35(2):247-56.

Satz M L, Stein M B, Serranle S, Braun M (1980) Mechanism of immune transfer by RNA extracts. Mol Cell Biochem 33:105.

Schloot NC, Willemen S, Duinkerken G, de Vries RR, Roep BO. (1998). Cloned T cells from a recent onset IDDM patient reactive with insulin B-chain. $J$ Autoimmun 11(2): 169-75.

Siemion, I.Z.; Cebrat, M.; Kluczyk, A. The problem of amino acid complementarity and antisense peptides. Curr. Protein Pept .Sci. 2004, 5(6),507-27

Sodomann C-P, Maerker-Alzer G, Havemann K, Dienst C, Schultz H, Mitrenga D, Schumacher K, Martini GA. 1979. Transfer factor (TF) Treatment of patients with HBSAg-positive chronic active hepatitis. A prospective, controlled study. Klin. Wochenschr 57: 893-903.

Stein LD, Ledgley CJ, Sigal NH. 1983. Patterns of isotype commitment in human B cells: limiting dilution analysis of Epstein Barr virus-infected cells. J Immunol. 130(4):1640-5.

Swiatczak B, Tauber AI. 2018. Holoimmunity Revisited. Bioessays. 40(11):e1800117. doi: 10.1002/bies.201800117.

Talmage DW. 1986. The acceptance and rejection of immunological concepts. Annu Rev Immunol. 4:1-11. 
Teodorescu M. A hypothesis on the role of immune RNA in antibody variability. J Theor Biol. 1973 Nov 15;42(2):189-218.

Tsang KY, Fudenberg HH. 1986. Transfer factor and other T cell products. Springer Semin Immunopathol 9: 19-32.

Urbain-Vansanten G, Richard C, Bruyns C, Hooghe V, Van Acker A, Urbain J. 1974. High number of antigen-binding cells in unimmunized mice and possible occurrence of multispecific lymphocytes. Ann Immunol (Paris). 125(6):885-900.

Viza D. 1996. AIDS and transfer factor: Myths, certainties and realities. Biotherapy 9: 17-26.

Viza D, Vich JM, Philips J, Rosenfield F. 1985. Orally administered specific transfer factor for the treatment of herpes infections. Lymphokine Res 4(1): 27-30.

Viza D, Lefesvre A, Patrasco M et al. 1987. A preliminary report on three AIDS patients treated with anti-HIV specific transfer factor. J Exp Path 3: 653-659.

Viza D, Fudenberg HH, Palareti A, Ablashi D, De Vinci C, Pizza G. Transfer factor: an overlooked potential for the prevention and treatment of infectious diseases. Folia Biol (Praha). 2013;59(2):53-67.

Waldman SR, Gottlieb AA. 1975. Evidence for double stranded RNA region in antigenbinding RNP. Immunochemistry 12: 787-790.

Wang BS, Mannick JA (1968) Fractionation of immune RNA capable of transferring tumor-specific cytotoxicity. Cell Immunol 37:358

White SL, Johnson AG. Studies on the cellular site of action of macrophage RNAantigen complexes. Cell Immunol. 1976 Jan;21(1):56-69.

Wilson GB, Fudenberg HH. 1983. Is the controversy about 'transfer factor therapy' nearing an end? Immunology Today 4(6): 157-161.

Wilson GB, Morin ML, Stuart LD, Williams AM, Floyd E, Paddock GV, Just L \& Fudenberg HH. 1983. Transfer of cell-mediated immunity in vitro to human lymphocytes using dialyzable leukocyte extracts from immune burros. In: lmmunobiology of Transfer Factor. New York: Academic Press, pp. 213-29.

Wilson GB, Paddock GV, Fudenberg HH. 1982. Bovine 'transfer factor': an oligoribonucleopeptide which initiates antigen-specific lymphocytes responsiveness. Thymus.4(6):335-50.

Wilson GB, Paddock GV, Fudenberg HH. 1981. Effects of dialyzable leukocyte extracts with transfer factor activity on leukocyte migration in vitro. V. Antigen-specific 
lymphocyte responsiveness can be initiated by two structurally distinct polyribonucleopeptides. Thymus.2(4-5):257-6.

Xu Y, Zou W, Zhan X, Yang S, Xie D, Peng S. 2006. Preparation and determination of immunological activities of anti-HBV egg yolk extraction. Cell Molec Immunol 3(1):6771.

Yalow, R. (1981). In, Shropshire, W., Jr., Ed. The Joys of Research. The Smithsonian Institution Press: Washington DC, pp. 109-110.

Yuan L, Campbell DH. A unique low molecular weight antigen fragment associated with oligoribonucleopeptide in lymph nodes and spleen. Immunochemistry. 1971 Feb; 8(2): 185-99.

Yuan L, Campbell DH. The in vivo and in vitro immunogenicity and antigenic specificity of lymphoid antigen fragment-oligoribonucleopeptide conjugates. Immunochemistry. 1972 Jan;9(1):1-8.

Zuckerman K, Nemiait JA, Balcerzak SP, Lobugco AF. 1974. Immunologic specificity of transfer factor. J Clin Invest 54: 997-1000. 